\title{
Prevention of Proximal Junctional Kyphosis \& Failure Using Sublaminar Bands in a Hybrid Construct in Pediatric Kyphosis Deformity
}

\author{
CHRISTOPHER BATTISTA, MD, ${ }^{1}$ CHRISTOPHER WILD, MD, ${ }^{1}$ SARAH KREUL, MD, ${ }^{1}$ \\ MICHAEL ALBERT, MD ${ }^{2}$ \\ ${ }^{I}$ Department of Orthopedics, Wright State University, Dayton, Ohio, ${ }^{2}$ Department of Orthopedics, Dayton Children's Hospital, Dayton, Ohio
}

\begin{abstract}
Purpose: The purpose of this study was to evaluate short term proximal junctional kyphosis and failure (PJK/ $\mathrm{PJF}$ ) rates and clinical outcomes in patients who underwent posterior spinal fusion (PSF) and deformity correction using sublaminar bands in a hybrid construct.

Methods: This is a retrospective review of pediatric spinal deformity cases performed by a single surgeon from January 2008 to December 2012. One hundred thirty-six pediatric deformity patient charts were reviewed for inclusion into the study. All 136 patients reviewed had been operatively managed for a spinal deformity and were younger than 18 years of age. Our study's inclusion criteria comprised patients with a kyphosis greater than $60^{\circ}$, the use of sublaminar polyester bands in a hybrid surgical construct, and a minimum of 2 years of follow-up. Of the 136 spinal deformity cases reviewed, 17 cases met our inclusion criteria. No cases were excluded because of technical difficulty of band placement or for not using a hybrid construct with sublaminar bands (as it was the primary surgeon's principal construct of choice). PJK was defined as proximal junction sagittal Cobb angle (PJA) of at least $10^{\circ}$ greater than the preoperative measurement. This was assessed by comparison of preoperative and postoperative radiographs. Our hypothesis was that PSF performed with our technique would have a lower rate of PJK than previously reported with other methods of fixation.
\end{abstract}

Results: The range of the preoperative kyphosis was $62^{\circ}-111^{\circ}$, and postoperative kyphosis was $12^{\circ}-55^{\circ}$. There was one case of PJK $(5.8 \%)$ and no cases of PJF.

Conclusion: This study on short term outcomes of PSF using sublaminar bands in a hybrid technique for treatment of kyphosis demonstrated a lower rate of PJK than has been reported in prior studies. This technique protects the fixation within the upper instrumented vertebrae of long segment PSFs.

Other and Special Categories

Keywords: proximal junctional kyphosis, sublaminar bands, pediatric kyphotic deformity, posterior spinal fusion, proximal junctional failure

\section{INTRODUCTION}

Reportedly, $27 \%-38 \%$ of adolescent idiopathic scoliosis (AIS) patients ${ }^{1,2}$ and $30 \%-32 \%$ of Scheuermann's kyphosis ${ }^{3,4}$ patients undergoing posterior spinal fusions (PSF) experience the postoperative complications proximal junctional kyphosis (PJK) and proximal junctional failure (PJF); these are not only aesthetic issues-they can cause emotional injury as well as possible neurological complications. ${ }^{5}$ PJK is a condition defined as meeting 2 requirements determined by Glattes et $\mathrm{al}^{5}$ : (1) proximal junction sagittal Cobb angle (PJA) $\geq 10^{\circ}$, and (2) an increase of PJA $10^{\circ}$ or greater from preoperative measurements. On the other hand, PJF describes the failure of the spinal implants, fracture, or myelopathy due to compression of the spinal cord at the upper instrumented vertebrae (UIV).

Identified risk factors for developing PJK include interrupting the posterior spinous ligaments responsible for limiting excessive kyphotic flexion ${ }^{3,6}$ and rigid instrumentation with abrupt transitions from fused to mobile spinal segments. ${ }^{3,7}$ To our knowledge, there has been no published study correlating the use of sublaminar polyester bands in PSF with the prevention of PJK and PJF. The purpose of our study was to determine the efficacy of polyester sublaminar bands in preventing PJK in patients with kyphotic deformities undergoing PSF. 


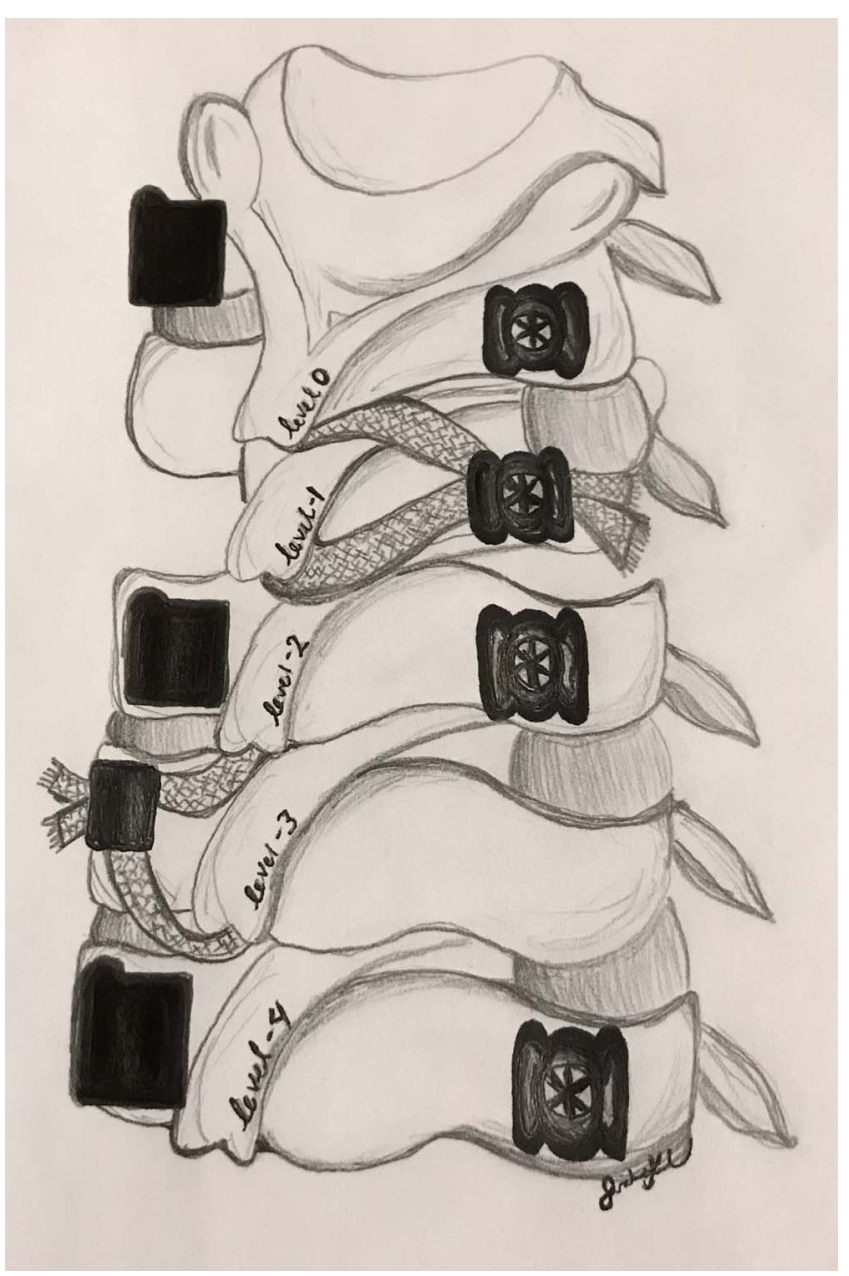

Figure 1. A medical drawing of our preferred hybrid construct. The most rostral level (level 0 ) is instrumented with pedicle screws. A unilateral sublaminar band is then placed just caudal (level -1) to the upper instrumented vertebrae to allow for a smooth transition from the construct to the native spine. The next level caudal (level -2 ) is instrumented with bilateral pedicle screws. Next, another unilateral sublaminar band is placed at the next caudal level (level-3) usually on the contralateral side of the level -1 sublaminar band. Variations in anatomy allow for some individualization of sublaminar band utilization. We demonstrate one "family" of implant construct in this drawing, but also approve of bilateral sublaminar band use at the level -1 and level -3 positions if desired. Moreover, note the preservation of the interspinous ligament and facet joints at the proximal aspect of the construct in an attempt to prevent proximal junctional kyphosis.

\section{METHODS}

This is a retrospective case series on 17 pediatric patients who underwent PSFs at Dayton Children's Hospital (Dayton, Ohio) between June 2008 and December 2012. All cases were performed by a single, fellowship trained, pediatric orthopedic surgeon. The criteria for inclusion consisted of patients with greater than $60^{\circ}$ kyphotic deformity treated with PSFs utilizing hybrid instrumentation with sublaminar polyester bands, inserted just caudal to the UIV, with at least a 2-year followup. No cases were excluded because of technical

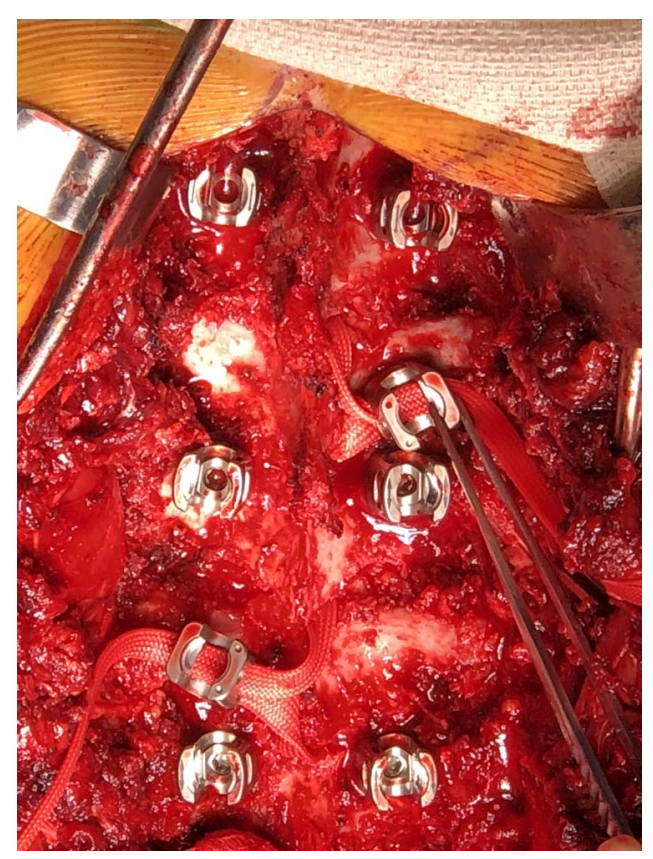

Figure 2. A clinical photograph demonstrating the proximal aspect of our construct with sublaminar bands used at alternating levels caudal to the upper instrumented vertebrae in an attempt to act as a softening transition from the stiffer construct to the native spine.

difficulty of band placement or for not utilizing a hybrid spinal construct with sublaminar bands (as it was the primary surgeon's principal construct of choice).

A standard, posterior, midline approach was used in all cases. After adequate exposure, facetectomies were performed at all levels except the UIV and 1 to 2 levels caudal. Care was taken to preserve the supraspinous ligament between the UIV and the vertebra immediately cranial. Sublaminar bands were utilized at the level immediately caudal to the UIV in order to "soften" the transition between the stiff construct and the native spine (see Figures 1 and 2). We believe that the best design for these constructs is to place pedicle screws at the rostral most level, as sublaminar bands would require damaging the interlaminar ligaments superior to the rostral level. Next, either unilateral or bilateral sublaminar bands are utilized at the level caudal to the UIV. Two levels caudal the UIV, bilateral pedicle screws are employed. Lastly, unilateral or bilateral sublaminar bands are then placed in the third level inferior to the UIV. This is a simple and easy construct to install and affords excellent clinical results. We chose variations of laterality of the sublaminar bands depending on individual anatomic differences noted at the time of surgery. Each surgical case was implemented with the same basic construct from 
Table 1. The 17 patients who were included in this study along with their age, gender, preoperative and 2-year postoperative kyphosis angles, spinal measurements, and the overall levels that were instrumented.

\begin{tabular}{|c|c|c|c|c|c|c|}
\hline Age & Gender & $\begin{array}{c}\text { PJA Postop } 2 \text { y } \\
\text { (Degree) }\end{array}$ & Kyphosis Preop & Kyphosis Postop 2 & C7-Plumbline $\pm 20 \mathrm{~mm}$ & Levels Instrumented \\
\hline 11 & $\mathrm{~F}$ & 26 & 72 & 36 & Normal & T2-Sacrum \\
\hline 19 & M & 9 & 86 & 55 & Normal & T3-L3 \\
\hline 13 & M & 9 & 82 & 27 & Normal & T3-L3 \\
\hline 11 & $\mathrm{~F}$ & 9 & 111 & 32 & Normal & T2-Sacrum \\
\hline 14 & $\mathrm{M}$ & 9 & 67 & 16 & Normal & T2-Sacrum \\
\hline 11 & M & 6.9 & 82 & 28 & Normal & T2-T3 \\
\hline 19 & $\mathrm{M}$ & 8.7 & 66 & 26 & Normal & T2-Sacrum \\
\hline 15 & $\mathrm{M}$ & 2 & 75 & 36 & Normal & $\mathrm{T} 4-\mathrm{T} 3$ \\
\hline 16 & M & 2.7 & 67 & 27 & Normal & T4-T3 \\
\hline 14 & $\mathrm{~F}$ & 8.8 & 67 & 19 & Normal & T2-Sacrum \\
\hline 11 & $\mathrm{M}$ & 3.4 & 69 & 26 & Normal & T2-Sacrum \\
\hline 15 & $\mathrm{~F}$ & 9.5 & 32 & 29 & Normal & T2-Sacrum \\
\hline 10 & M & 3.9 & 90 & 26 & Normal & T2-Sacrum \\
\hline 17 & $\mathrm{~F}$ & 4.5 & 69 & 38 & Normal & T2-L2 \\
\hline 12 & $\mathrm{~F}$ & 1 & 86 & 26 & Normal & T2-Sacrum \\
\hline 10 & $\mathrm{~F}$ & 4 & 84 & 12 & Normal & T2-Sacrum \\
\hline 15 & $\mathrm{~F}$ & 8 & 74 & 26 & Normal & T4-L4 \\
\hline
\end{tabular}

Abbreviation: PJA, proximal junctional saggital Cobb angle.

cranial to caudal consisting of bilateral pedicle screws at the UIV, sublaminar band(s), bilateral pedicle screws, and sublaminar band(s). The typical construct is illustrated in Figures 3 and 4 in a patient with Scheuermann's kyphosis.

One hundred thirty-six cases were reviewed and 17 were found to meet the inclusion criteria. These cases were evaluated for PJA and sagittal balance values by comparison of preoperative and inhospital postoperative radiographs to outpatient follow-up imaging obtained at least 2 years following the index procedure. All roentgenograms were performed with the patient upright utilizing antero-
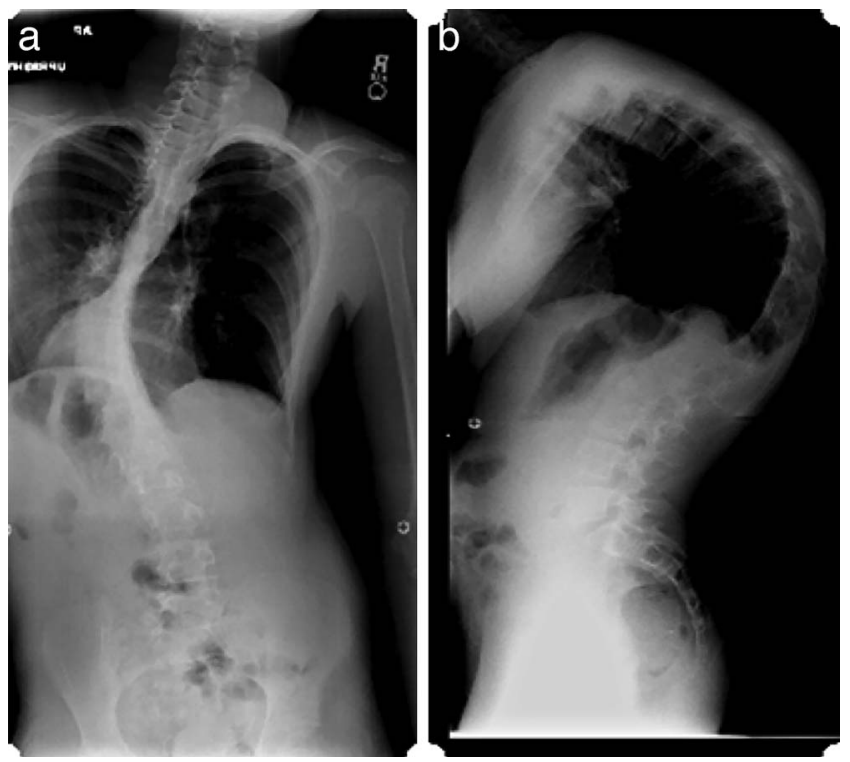

Figure 3. The preoperative radiographs of a 15-year-old boy with neuromuscular kyphosis treated surgically utilizing the described technique. posterior and lateral images and measuring the kyphosis via standard Cobb technique. PJA was determined by measuring the angle from the caudal endplate of the UIV to the cephalic endplate of the vertebra 2 levels proximally. A PJA $\geq 10^{\circ}$ at followup of at least 2 years was used to define PJK. Sagittal balance was calculated by measuring the distance from the $\mathrm{C} 7$ plumb line to superior posterior end of the S1 vertebral body, and if the C7 plumb line was within $20 \mathrm{~mm}$ it was considered normal sagittal balance. These angles were gathered

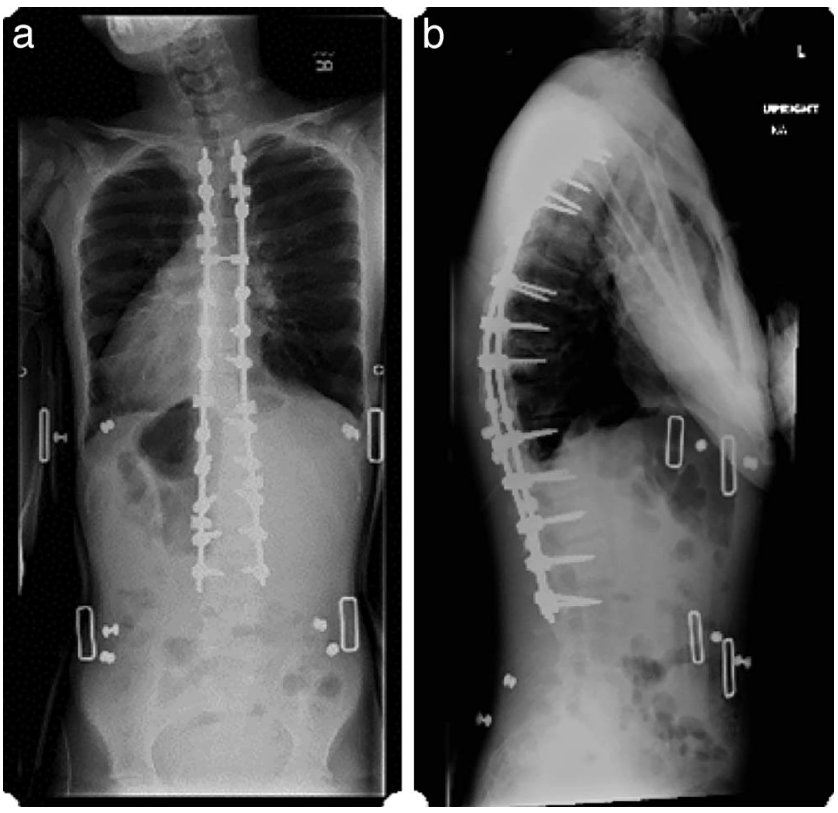

Figure 4. The postoperative radiographs of a 15-year-old boy with neuromuscular kyphosis treated surgically utilizing the described technique. 
collaboratively between the 3 authors for all patients.

\section{RESULTS}

All of the 17 participants were closely followed and data were collected and recorded for each postoperative visit all the way to their regularly scheduled 2-year postoperative visit. Out of the 17 patients being evaluated, 5 had neuromuscular kyphosis (NK) secondary to cerebral palsy while 2 were secondary to Rett's syndrome; 5 had congenital kyphosis, 2 had Scheuermann's kyphosis, 1 had Duchenne's muscular dystrophy, 1 kyphosis was secondary to an arachnoid cyst, and 1 kyphosis was secondary to spinal muscular dystrophy. Eight of the 17 patients were female and the remaining 9 were male with an average age of $14 \pm 3$ years of age (range, 10-19 years).

Following radiographic measurement and comparison, the average kyphosis decreased from $77^{\circ}$ $\left( \pm 12^{\circ}\right)$ preoperatively to $29^{\circ}\left( \pm 10^{\circ}\right)$ at the 2-year follow-up evaluation. The sagittal balance for all patients was deemed to fall within the normal range $( \pm 20 \mathrm{~mm}$ ) based on the radiographic C7 plumb-line measurements. Only 1 patient out of $17(5.8 \%)$ presented with PJK at the 2-year follow-up and the average PJA for all 17 patients was $7^{\circ}\left( \pm 6^{\circ}\right)$. See Table 1 for a full representation of the preoperative, 2-year postoperative, and PJA spinal measurements as well as the levels instrumented in our patient cohort.

There were $2(11.8 \%)$ major complications, defined as a complication necessitating a return to the operating room. The first case had a loss of intraoperative motor evoked potentials (MEPs) in the right leg resulting in premature surgery cessation. The patient had an emergent MRI, which was found to be normal. Subsequently, there was return of normal neurologic function in the pediatric intensive care unit and the patient returned to surgery 5 days later to complete the spinal fusion without further complication. The loss of monitoring to the lower extremity was noted during deformity correction and did not correlate with passage of sublaminar bands. The second case involved the removal of an iliac screw at 6 months postoperatively due to prominence and associated pain.

Minor complications were defined as those that did not necessitate operative intervention. In our cohort, these included 1 patient who required a prolonged intensive care unit stay following correction of a $110^{\circ}$ kyphosis deformity, a right sided pneumothorax that resolved with chest tube placement, a sacral decubitus ulcer that resolved with local wound care, and a patient requiring a nasogastric tube placement for enteral feedings. Overall there were 6 complications $(32.3 \%)$.

\section{DISCUSSION}

Studies have shown that 2 of the strongest risk factors for development of PJK include posterior spinous ligament disruption ${ }^{3,6}$ and abrupt transition from a rigid instrumented vertebrae to a more mobile cephalic vertebrae. ${ }^{3,7}$ In our technique, the posterior ligamentous structures attached to the UIV were meticulously preserved by using pedicles screws in this location as opposed to the sublaminar bands. In many studies, these proximally based screws at the UIV have been shown to be susceptible to pulling out. To prevent this, most previous studies focus on strategies that mitigate the rigidity of a long segment fusion. However, others have attempted to prevent this by improving the strength of the fixation within the UIV by augmenting the available bone stock with cement. Cement augmentation has shown some promise in the adult population, yet other options are still available. ${ }^{8}$ We theorized that our technique of utilizing a hybrid construct provides a novel method of protecting the proximal fixation within the UIV, while still being able to appropriately correct spinal deformity.

The sublaminar bands we utilized in our constructs offer a unique advantage in spinal deformity correction. Their broad surface area of contact to the lamina provide a mechanical advantage by preventing posterior screw pull-out from the large moment arm produced by the spinal construct. The bands are tensioned during implantation and a final set screw is then able to lock the band to the rod and the rod to the tulip head, ultimately forming a snug construct against the lamina. Thus, the sublaminar bands protect against screw pullout are superior to wires that may cut through the lamina.

The $5.8 \%$ frequency of PJK in our study compares favorably against all other determined incidence rates noted within the literature. Studies by Denis et $\mathrm{al}^{3}$ and Lonner et $\mathrm{al}^{4}$ place the frequency of PJK in Scheuermann's kyphosis patients between $30 \%$ and $32 \%$, while a study by Syed et $\mathrm{al}^{9}$ found a PJK rate of $26 \%$ after PSF in neuromuscular 
scoliosis patients. The marked improvement in PJK incidence we have noted in our patient cohort is unprecedented within our field of study and patient population.

The safety of sublaminar bands has been a subject of debate. Desai et al, ${ }^{10}$ in a study examining PSFs utilizing sublaminar bands in pediatric patients suffering from neuromuscular spinal dystrophies, questioned the safety of sublaminar bands in the pediatric patient population due to a high rate of neurological adverse events $(10 \%)$. However, a study performed by Polirsztok et $\mathrm{al}^{11}$ found similar or lower neurologic, vascular, and pleural complication rates in the use of sublaminar bands in AIS patients $(2.1 \%)$ compared with sublaminar wires $(17 \%)$ and comparable to pedicle screws (1.8\%). In our study, a neurologic complication occurred in 1 of 17 patients $(5.8 \%)$ and was not a permanent deficit. Furthermore, the neurologic alterations that were noted were not seen during band passage, but rather with deformity correction. The differences in neurologic complication rate indicate a need for further investigation into the safety of sublaminar bands in a pediatric patient population with a larger sample size.

This study does have weaknesses. First, this is a retrospective study where both clinical and radiographic data are limited to what was obtained in the past. Second, the number of patients who were included in our study is relatively small, yet comparable to the other studies investigating PJK in kyphotic deformity correction within the literature. ${ }^{3,4,12}$ Third, the patients included in our series have different etiologies to their kyphosis. Most previous studies on pediatric kyphotic deformity correction focus on Scheuermann's kyphosis. Many of the other etiologies that were included predispose patients to having lower bone mineral density or more dysplastic posterior spinal elements. This could make obtaining adequate fixation in the UIV more problematic, yet our series had a lower incidence of PJK than previously published series. ${ }^{3,4}$ Lastly, we have only 2 years of clinical and radiographic follow-up. Although this seems to be a short time frame, it is likely adequate to detect our outcomes of PJK and PJF. Kim et a ${ }^{13}$ demonstrated that PJK will present within 2 years after deformity correction, and the majority of the radiographic progression occurs within the first 8 weeks after surgery.
To our knowledge, this is the first study to describe the use of sublaminar bands in the correction of pediatric kyphosis and prevention of PJK. In our experience, sublaminar bands provide an effective alternative to pedicle screws and sublaminar wires in PSFs while reducing the rate of PJK. Furthermore, the use of sublaminar bands in pediatric neuromuscular deformity patients may be indicated due to poor bone mineral density. Sublaminar bands provide a larger surface area contact than sublaminar wires and ultimately decrease the chances of pull out failure at the pedicle screws within the UIV. The use of sublaminar bands in the prevention of PJK in pediatric patients with kyphotic deformities may have clinical application that extends to the adult patient populations. Specifically, they may be considered an adjunct in patients with osteoporosis or poor bone quality.

\section{CONCLUSION}

The published high incidence rates of PJK following PSF are detrimental for patients aesthetically and functionally. The surgical technique utilizing sublaminar bands in a hybrid construct form at the UIV seems to provide an effective method in the prevention of PJK following PSF in pediatric kyphosis deformity surgery.

\section{REFERENCES}

1. Wang J, Zhao Y, Binghua S, et al. Risk factor analysis of proximal junctional kyphosis after posterior fusion in patients with idiopathic scoliosis. Injury. 2010;41(4): 415-420.

2. Kim YJ, Lenke LG, Bridwell KH, et al. Proximal junctional kyphosis in adolescent idiopathic scoliosis after 3 different types of posterior segmental spinal instrumentation and fusions: incidence and risk factor analysis of 410 cases. Spine (Phila Pa 1976). 2007;32(24): 2731-2738.

3. Denis F, Sun EC, Winter RB. Incidence and risk factors for proximal and distal junctional kyphosis following surgical treatment for Scheuermann kyphosis: minimum five-year follow-up. Spine (Phila Pa 1976). 2009;34(20):729-734.

4. Lonner BS, Newton P, Betz R, et al. Operative management of Scheuermann's kyphosis in 78 patients: radiographic outcomes, complications, and technique. Spine (Phila Pa 1976). 2007;32(24):2644-2652.

5. Glattes RC, Bridwell KH, Lenke LG, et al. Proximal junctional kyphosis in adult spinal deformity following long instrumented posterior spinal fusion: incidence, outcomes, and risk factor analysis. Spine (Phila Pa 1976). 2005;30(14):16431649.

6. Cahill PJ, Wang W, Asghar J, et al. The use of transition rod may prevent proximal junctional kyphosis in the thoracic 
spine after scoliosis surgery: a finite element analysis. Spine (Phila Pa 1976). 2012;37(12):687-695.

7. Lee CK, Langrana NA. Lumbosacral spinal fusion: a biomechanical study. Spine (Phila Pa 1976). 1984;9(6):574-581.

8. Martin CT, Skolasky RL, Mohamed AS, Kebaish KM. Preliminary results of the effect of prophylactic vertebroplasty on the incidence of proximal junctional complications after posterior spinal fusion to the low thoracic spine. Spine Deform. 2013;1(2):132-138.

9. Syed I, Brasher A, Hammerberg K, Sturm P. The effect of proximal fixation on the development of junctional kyphosis in neuromuscular scoliosis following segmental posterior spinal instrumentation and fusion. Spine J. 2009;9(10):88S.

10. Desai S, Sayama C, Vener D, et al. The feasibility and safety of sublaminar polyester bands in hybrid spinal constructs in children and transitional adults for neuromuscular scoliosis. J Neurosurg Pediatr. 2015;15(3):328-337.

11. Polirsztok E, Gavaret M, Gsell T, et al. Sublaminar bands: are they safe? Eur Spine J. 2014;24(7):3594.

12. Yanik HS, Ketenci IE, Polat A, et al. Prevention of proximal junctional kyphosis after posterior surgery of Scheuermann kyphosis: an operative technique. J Spinal Disord Tech. 2015;28(2):E101-E105.

13. Kim YJ, Bridwell KH, Lenke LG, et al. Proximal junctional kyphosis in adult spinal deformity after segmental posterior spinal instrumental and fusion: minimum five-year follow-up. Spine (Phila Pa 1976). 2008;33(20):2179-2184.

Disclosures and COI: The senior author (author \#4) is a paid consultant for OrthoPediatrics and serves on a number of committee/boards within professional societies. See a detailed list at: http:// www7.aaos.org/education/disclosure/search.as px\#sthash.XYiOse7F.dpuf. The remaining authors have nothing to disclose. For this type of study formal consent is not required. Informed consent was obtained from all individual participants included in the study.

Published 21 December 2018

This manuscript is generously published free of charge by ISASS, the International Society for the Advancement of Spine Surgery. Copyright (C) 2018 ISASS. To see more or order reprints or permissions, see http://ijssurgery.com. 